\title{
Les mots du climat
}

Jean Poitou et Pascale Braconnot

edpsciences 


\section{Des mêmes auteurs}

Le climat: la Terre et les Hommes, Jean Poitou, Pascale Braconnot et Valérie MassonDelmotte, EDP Sciences, 2015, ISBN : 978-2-7598-0881-6

\section{Remerciements}

Nous tenons à remercier Valérie Masson-Delmotte pour l'aide précieuse qu'elle nous a apportée pour établir la liste des termes à définir dans cet ouvrage. Merci à notre éditeur qui nous a judicieusement incités à enrichir l'ouvrage au-delà d'un simple glossaire. Et nous remercions particulièrement Nada Caud pour sa relecture attentive du manuscrit.

Cet ouvrage a été financé par le projet JPI-Belmont PACMEDY (ANR-15-JCLI-0003-01).

ISBN (ebook) : 978-2-7598-2545-5

DOI : $10.1051 / 978-2-7598-2545-5$

Cet ouvrage est publié en Open Access sous licence creative commons CC-BY-NC-ND (https://creativecommons.org/licenses/by-nc-nd/4.0/fr/) permettant l'utilisation non commerciale, la distribution, la reproduction du texte, sur n'importe quel support, à condition de citer la source.

(C) Les auteurs, 2021 